\title{
Meloxicam quantification in rabbit plasma by RP-HPLC: optimization and application to pharmacokinetic study
}

\author{
Nitin Salunkhe ${ }^{1,2}$, Namdeo Jadhav ${ }^{1 *}$ and Somnath Bhinge ${ }^{3}$
}

\begin{abstract}
Background: The goal of the proposed study was to validate a rapid, simple, an accurate, robust, and sensitive bioanalytical method for quantifying Meloxicam and Lornoxicam (as internal standard) in rabbit plasma.

Result: Limit of detection and limit of quantification for Meloxicam were found to be 0.0081 and $0.1035 \mu \mathrm{g} \mathrm{mL}^{-1}$, respectively. The bioanalysis was continued according to standard guidelines and successfully used for bioavailability studies of meloxicam after single dose administration of pure drug and the formulation in rabbit plasma. Finally, obtained results proved its simplicity and an efficiency to be applied for the therapeutic drug monitoring and bioequivalence studies.

Conclusion: Therefore, the set RP-HPLC bioanalysis is simple, convenient, and acceptable to analyze meloxicam in bulk and pharmaceutical formulations in rabbit plasma.
\end{abstract}

Keywords: Bioanalysis, Meloxicam, Lornoxicam, Validation, Pharmacokinetic Study, Rabbit Plasma

\section{Background}

Chemically, Meloxicam (MLC) is 4-hydroxy-2-methyl- $\mathrm{N}$-(5methyl-2-thiazolyl)-2H-1,2-benzothiazine-3-carboxamide-1, 1-dioxide (Fig. 1a) [1], a new nonsteroidal anti-inflammatory drug (NSAID) derived from enolic acid, which exhibits cyclooxygenase (COX)-2 selectivity over COX-1 as described in a randomized double-blind study [2]. Meloxicam is used in the treatment of rheumatoid arthritis, osteoarthritis, and other joint diseases [3].

Plentiful UV-VIS, HPLC, HPLC-MS/MS, LC-MS, LCMS-MS, LC-ESI-MS/MS, LC-MS/TOF, and LC-MS analytical methods have been documented for quantifying the MLC from different formulation either alone or in combination with pharmacotherapeutic agents in biological fluid [1, 4-18]; a couple of them namely were employed liquid-liquid extraction or protein precipitation extraction (PPE) approach for quantification of

\footnotetext{
* Correspondence: nrjadhav18@rediffmail.com

'Department of Pharmaceutics, Bharati Vidyapeeth College of Pharmacy, Kolhapur, Maharashtra 416013, India

Full list of author information is available at the end of the article
}

MLC from biological sample [5, 7, 14]. In spite of that, the reported approaches are time-consuming; some of them used organic solvents and hazardous solvents for the extraction process, and some of which reported much less recovery which may be due to the drug loss during the transfer. Moreover, most of which followed solid-phase and liquid-liquid extraction techniques which required a more complex process [19]. In addition, the strong chemical bonds between plasma proteins and pharmacotherapeutic agents lead to a decrease in the efficiency of extraction, thus completely hampering the removal of pharmacotherapeutic agents, and consequently, a lower recovery [20]. Though solidphase extraction has been reported by Miyamoto et al. to quantify the MLC from biological sample, this method requires expensive equipment [1]. Couple of the bioanalytical methods used to quantify the MLC did not use the internal standard, which seemed to be a limitation of the reported method; some of which had been used but were complex in nature $[8,11,12,15,17]$.
Springer Open (c) The Author(s). 2020 Open Access This article is licensed under a Creative Commons Attribution 4.0 International License, which permits use, sharing, adaptation, distribution and reproduction in any medium or format, as long as you give appropriate credit to the original author(s) and the source, provide a link to the Creative Commons licence, and indicate if changes were made. The images or other third party material in this article are included in the article's Creative Commons licence, unless indicated otherwise in a credit line to the material. If material is not included in the article's Creative Commons licence and your intended use is not permitted by statutory regulation or exceeds the permitted use, you will need to obtain permission directly from the copyright holder. To view a copy of this licence, visit http://creativecommons.org/licenses/by/4.0/. 
A<smiles>Cc1cnc(NC(=O)C2=C(O)c3ccccc3S(=O)(=O)N2C)s1</smiles>

MW $=351.403 \mathrm{~g} \mathrm{~mol}^{-1}$
B<smiles>CN1C(C(=O)Nc2ccccn2)=C(O)c2sc(Cl)cc2S1(=O)=O</smiles>

$\mathrm{MW}=371.819 \mathrm{~g} \mathrm{~mol}^{-1}$

Fig. 1 Chemical structure of a Meloxicam and $\mathbf{b}$ Lornoxicam

Therefore, it would be very beneficial to find a specific simple and efficient bioanalytical method for the rapid estimation of MLC in biological samples and also to reduce the above mentioned deficiencies. Furthermore, the binding ability of MLC to plasma proteins requires determining whether other related drugs mediate MLC binding, and vice versa [20]. Precipitation of proteins is the simplest way to extract most of the protein from the plasma and also involves minimal processing steps, which is why protein precipitation approach is used in pharmacokinetics analysis [21]. Biochemical analysis of MLC in plasma should be investigated in accordance with the FDA standards to ensure the safety and efficacy of marketed formulations [22].

The present research was carried out by considering the observations for estimating MLC in rabbit blood plasma using a simple extraction technique with specific and appropriate internal standards (Fig. 1b) to establish and validate a fast, simple bioanalytical reversed-phase HPLC-UV process along with randomized single-dose pilot study to test the bioavailability of MLC in a formulation.

\section{Methods}

\section{Chemicals and reagents}

HPLC grade methanol and acetonitrile (ACN) were purchased from MERCK India Pvt. Ltd. Meloxicam (MLC) and Lornoxicam (LRC) were obtained from Macleods Pharmaceuticals Ltd. (Mumbai-400093, Maharashtra, India), and all other chemicals were of analytical grade. Double-distilled water was used for preparing mobile phase solutions. The $0.45 \mu \mathrm{m}$ nylon filters were purchased from Sigma-Aldrich, India.

\section{Instrumentation}

Systronics-HPLC (Isocratic mode) equipped with plus pump (Liquid Chromatography-100), UV/Vis detector (Liquid Chromatography-UV 100), and installed Shanghai Wufeng operating software. The separation was carried out on C8 Capcell pack DDS5 column along with $5 \mu \mathrm{m}$ particle size and a length of $0.46 \mathrm{~cm} \times 25 \mathrm{~cm}$.

\section{Chromatographic condition}

Fifteen millimolar phosphate buffer having $\mathrm{pH}$ 4.7: methanol in the proportion of $40: 60 \mathrm{v} / \mathrm{v}$ was prepared as a mobile phase, and then the mobile phase was degassed using sonicator for continuous $30 \mathrm{~min}$. The final solution was filtered by using Millipore vacuum filter system with $0.45 \mu \mathrm{m}$ membrane filter paper. The prepared mobile phase was run to maintain flow rate at $1.0 \mathrm{~mL}$ $\mathrm{min}^{-1}$. UV 100 detector was set at $357.0 \mathrm{~nm}$ for the column effluence.

\section{Preparation of stock solution}

One hundred milligrams of MLC and LRC were transferred into a separate $100 \mathrm{~mL}$ volumetric flask, and then the $20 \mathrm{~mL}$ mobile phase was added and mixed with continuous shaking. The clear solution was ultra-sonic for a further $15 \mathrm{~min}$ and the resulting solution was then diluted into the target with the same solvent in order to obtain a final solution with a concentration of $1000 \mu \mathrm{g}$ $\mathrm{mL}^{-1}$. Furthermore, concentration ranges of MLC from 0.5 to $25 \mathrm{mg} \mathrm{mL}^{-1}$ were prepared using stock solution of MLC further diluted with mobile phase and stored under standard condition. Additionally, the working standard solution of LRC (internal standard) was prepared a final concentration of $40 \mu \mathrm{g} \mathrm{mL}{ }^{-1}$ with an addition of LRC stock solution.

\section{Extraction procedure}

One hundred microliteres of the plasma and $50 \mu \mathrm{L}$ of respective concentrations $(0.50,1.00,2.00,5.00,10.00$, $15.00,20.00$, and $25.00 \mu \mathrm{g} \mathrm{mL}^{-1}$ ) of MLC solutions were dropped into eight labeled microcentrifuge tubes (1500 $\mu \mathrm{L}$ capacity), and then all prepared samples were vortexed for a minute. Subsequently, $50 \mu \mathrm{L}$ of LRC (40 $\mu \mathrm{g}$ $\mathrm{mL}^{-1}$ ) as an internal standard was added into resultant each concentration solution. Repeatedly, the all resultant solutions were vortexed for a minute with following medium speed. Further, $100 \mu \mathrm{L}$ of protein precipitating agent namely $\mathrm{ACN}$ was dropped in each labeled tube and the all resultant solution were vortex for $2 \mathrm{~min}$ under medium speed. Finally, the all prepared samples 
were precipitated at room temperature, followed by centrifugation at $5000 \mathrm{rpm}$ for continuous $15 \mathrm{~min}$, and the supernatant was filtered through a $0.45 \mu \mathrm{m}$ filter paper. At last, $20 \mu \mathrm{L}$ of all samples were assessed under selected chromatographic condition.

\section{Methods}

In order to estimating MLC in rabbit plasma with precise, accurate, and reproducible bioanalytical reversephase HPLC-UV method, various solvent combination for mobile phases, stationary phases, and MLC preparation techniques have been assessed; however, the proposed mobile phase, stationary phase, MLC preparation techniques, $\lambda \max$, etc. have been found to be appropriate for quantitative determination of MLC and internal standard. Finally, the proposed optimized and developed method for MLC was validated for selected parameters according to standard guidelines [22, 23].

\section{System suitability test}

Prior to the analysis of each batch of samples, tests were carried out to confirm the reproducibility of the chromatographic system according to USP24/NF19 [24]. However, selected criteria namely retention time (RT), theoretical plate number $(N)$, and tailing factor $(\mathrm{T})$ are based on the actual performance of the method, as specified during its validation [25]. Selected parameters for the MLC peak were assessed to determine the percent coefficient of variation (\% RSD) for the system suitability test.

\section{Linearity}

The linearity was confirmed using eight concentrations that range from 0.50 to $25.00 \mu \mathrm{g} \mathrm{mL}^{-1}$ of MLC solution. The linearity experiment was tested to detect the response of the detector in linear with different concentrations of MLC solutions spiked in rabbit plasma, i.e., 0.50, $1.00,2.00,5.00,10.00,15.00,20.00$, and $25.00 \mathrm{Lg} \mathrm{mL}^{-1}$ with fixed concentration of LRC solution as an internal standard using the abovementioned extraction method. Finally, the prepared concentrations were injecting into the HPLC system and the calibration curves were constructed by plotting peak area of MLC versus concentrations of MLC, and the correlation coefficient, slop, and intercept were obtained from regression equations. Signal-to-noise ratios have been used to determine the limit of detection (LOD) and limit of quantification (LOQ) of MLC [26].

\section{LLOQ (sensitivity)}

The LLOQ is the lowest sample analysis concentration, can be accurately and precisely quantified, can be considered the lowest calibration curve point, and should be considered at least 5 times the blank sample [27-29].

\section{Precision}

The quality control (QC) sample having a concentration of $0.50,5.00$, and $25.00 \mu \mathrm{g} \mathrm{mL}^{-1}$ are represented in the calibration curves of the MLC between the low, medium, and high ranges in order to determine the accuracy and precision of the system being developed. Six injections of each concentration $\left(0.50,5.00\right.$, and $\left.25.00 \mu \mathrm{g} \mathrm{mL} \mathrm{m}^{-1}\right)$ were tested for the intraday study on the same day, while nine injection of each concentration $(0.50,5.00$, and $25.00 \mu \mathrm{g} \mathrm{mL} \mathrm{m}^{-1}$ ) were tested for an interday variation over a period of 15 day and finally observed results were used to calculate \% RSD in precision, whereas accuracy was expressed as a percentage of the theoretical concentration [30].

\section{$\%$ Recovery (accuracy)}

In order to confirm the accuracy of the proposed method, three different concentrations of linearity curve covering the lower, medium, and higher ranges with a concentration of $0.50,5$, and $25 \mu \mathrm{g} \mathrm{mL} \mathrm{m}^{-1}$ respectively were assessed. Absolute and relative recovery of the same nominal concentration for MLC was calculated by adding known quantities of MLC to the MLC free rabbit plasma. At the same nominal concentrations, absolute recoveries were determined with the peak area of the extracted QC samples compared to the peak area of the recovery standards [30-33].

\section{Robustness}

In proposed study, robustness is used to determine the effect of a small but deliberate variance in the flow rate of the pump at 0.9 and $1.1 \mathrm{~mL} \mathrm{~min}^{-1}$; $\mathrm{pH}$ of the phosphate buffer at 4.6 and 4.7: and percent of the phosphate buffer on 38 and $42 \%$ in the mobile phase and were noted in \% RSD.

\section{Specificity}

Checking any interference of an endogenous compound or corresponding placebo in the retention time of the MLC and LRC.

\section{Stability}

Stock solutions stability study was evaluated in three ways viz: (1) the freshly prepared plasma rabbit sample was accessed and then held overnight at a temperature of $15-20^{\circ} \mathrm{C}$ for $24 \mathrm{~h}$ and then re-injected into the HPLC device; (2) rabbit plasma samples were stored overnight in the freezer at $-20^{\circ} \mathrm{C}$, collected at room temperature, and injected within $1 \mathrm{~h}$ after thawing thoroughly; and (3) standard stock solutions stored for 1 week at $-20{ }^{\circ} \mathrm{C}$ in freezer, brought to room temperature, and injected within $1 \mathrm{~h}$ after thawing. 


\section{Application to bioavailability studies}

In a single dose pilot study with randomized, single dose, crossover protocol, bioavailability and bioequivalence of bulk MLC (as a reference) and its tablet formulation (MELFLAM tab, Cipla Ltd, Mumbai) were assessed via simple extraction procedures namely protein precipitation technique. The bioavailability and bioequivalence study of pure MLC and MELFLAM tabs was checked using albino rabbits (Protocol No. BVCPK/CPCSEA/IAEC/1/5) of either sex weighing between 2.100 and $3.200 \mathrm{~kg}$ and sustained under standard conditions as defined by IAEC BVCOP, Kolhapur-416013, MS, INDIA. The selected six rabbits were equally divided into standard and test group; the standard and test group received suspension of pure MLC drugs and MELFLAM tab respectively. Subsequently, an aliquot of $1 \mathrm{~mL}$ of blood sample was drawn from the marginal ear rabbit vein before and after administration of the MLC test sample and the MELFLAM tab (15 mg) sample at intervals $0,0,5,1,2,3,4,6,8,12,24,36$, and 48 ho, as shown by the Shermer process [34]. The collected rabbit blood samples were then placed in Vacutainer Heparin Tubes and followed the centrifugation for 10 min at $4{ }^{\circ} \mathrm{C}$ at a speed of $10,000 \mathrm{rpm}$, and then the supernatant was collected and stored in brown tubes at $-30{ }^{\circ} \mathrm{C}$ until analysis time. The pharmacokinetic parameters namely maximum peak plasma concentration $\left(C_{\max }\right), T_{\max }$, area under curve (AUC), mean residence time (MRT), half-life at the terminal phase $\left(T_{1 / 2}\right)$, and elimination rate constant $(\mathrm{Ke})$ were assessed under non-compartmental moment analysis model.

\section{Statistical analysis}

$\mathrm{AUC}_{0-\mathrm{t}}, C_{\max }$, and $\mathrm{AUC}_{0-\infty}$ were considered as crucial variables in bioequivalence study of MLC (in bulk and formulation) and were checked with the means of analysis of variance (ANOVA). 90\% CI was calculated using Log transformed data [35, 36].

\section{Results}

The developed bioanalytical method was validated as per United State- Food \& Drug Administration guidelines $[20,22,28,29]$.

\section{System suitability test}

The theoretical plate number $(N)$ and tailing factors for MLC $\left(15 \mu \mathrm{g} \mathrm{mL} \mathrm{m}^{-1}\right)$ were found to be $2251.50 \pm 1.9992$ and $1.69 \pm 1.7553$ respectively. The chromatographic conditions described ensured adequate retention and asymmetry for drug compounds [26, 37]. Therefore, the retention time of MLC was noted at $6.2398 \pm 0.8608$ min (Table 1). The theoretical plate were observed in the range of 2210 to 2339, whereas tailing factor of the MLC were noted in the range of 1.65 to 1.74 . However, it was found that MLC retention time was within 6.1769 to $6.2914 \mathrm{~min}$.

\section{Specificity}

According to the chromatogram results, no interference from impurity, excipients, or additives were found and the all present additives in tablets were practically insoluble in mobile phase (Fig. 2).

\section{Linearity}

Linear calibration curves was observed after plotting peak area versus concentration of MLC over the concentration range of $0.5-25 \mu \mathrm{g} \mathrm{mL} \mathrm{m}^{-1}$ and the correlation coefficients were found to be 0.9940 , whereas intercept and slope were found to be -576.45 and 1324.25 respectively for MLC (Table 2). Limit of detection and limit of quantification for MLC in rabbit plasma samples were found to be 0.0081 and $0.1035 \mu \mathrm{g} \mathrm{mL}{ }^{-1}$ respectively and proved the sensitivity of the proposed bioanalytical methods.

\section{LLOQ (sensitivity)}

Diluting known concentrations of MLC in rabbit plasma was used to check the LLOQ; however, the proposed assay method offered an LLOQ of $0.50 \mu \mathrm{g} \mathrm{mL}^{-1}$ for

Table 1 System suitability test for MLC $(n=6)$

\begin{tabular}{|c|c|c|c|c|c|c|c|}
\hline \multirow{2}{*}{$\begin{array}{l}\text { Obs. No. } \\
1\end{array}$} & \multirow{2}{*}{$\begin{array}{l}\text { Concentration }\left(\mu \mathrm{g} \mathrm{mL}^{-1}\right) \\
15\end{array}$} & \multicolumn{2}{|c|}{ Peak area } & \multirow{2}{*}{$\begin{array}{l}\text { Area ratio } \\
0.8809\end{array}$} & \multirow{2}{*}{$\begin{array}{l}\text { Retention time } \\
6.2681\end{array}$} & \multirow{2}{*}{$\begin{array}{l}\text { Theoretical plate } \\
2235\end{array}$} & \multirow{2}{*}{$\begin{array}{l}\text { Tailing facto } \\
1.65\end{array}$} \\
\hline & & 17686.2 & 20075.2 & & & & \\
\hline 2 & 15 & 17807.8 & 20496.7 & 0.8688 & 6.1769 & 2210 & 1.69 \\
\hline 3 & 15 & 17864.2 & 20267.1 & 0.8814 & 6.2914 & 2250 & 1.74 \\
\hline 4 & 15 & 17388.7 & 20705.5 & 0.8398 & 6.1985 & 2250 & 1.68 \\
\hline 5 & 15 & 17773.5 & 20789.5 & 0.8549 & 6.3021 & 2225 & 1.68 \\
\hline 6 & 15 & 18098.9 & 20550.5 & 0.8807 & 6.2021 & 2339 & 1.70 \\
\hline Mean & & - & - & 0.8677 & 6.2398 & 2251.5 & 1.69 \\
\hline S.D. & & - & - & 0.0171 & 0.0537 & 45.5137 & 0.0296 \\
\hline$\%$ RSD. & & - & - & 1.9804 & 0.8608 & 2.0214 & 1.7553 \\
\hline
\end{tabular}




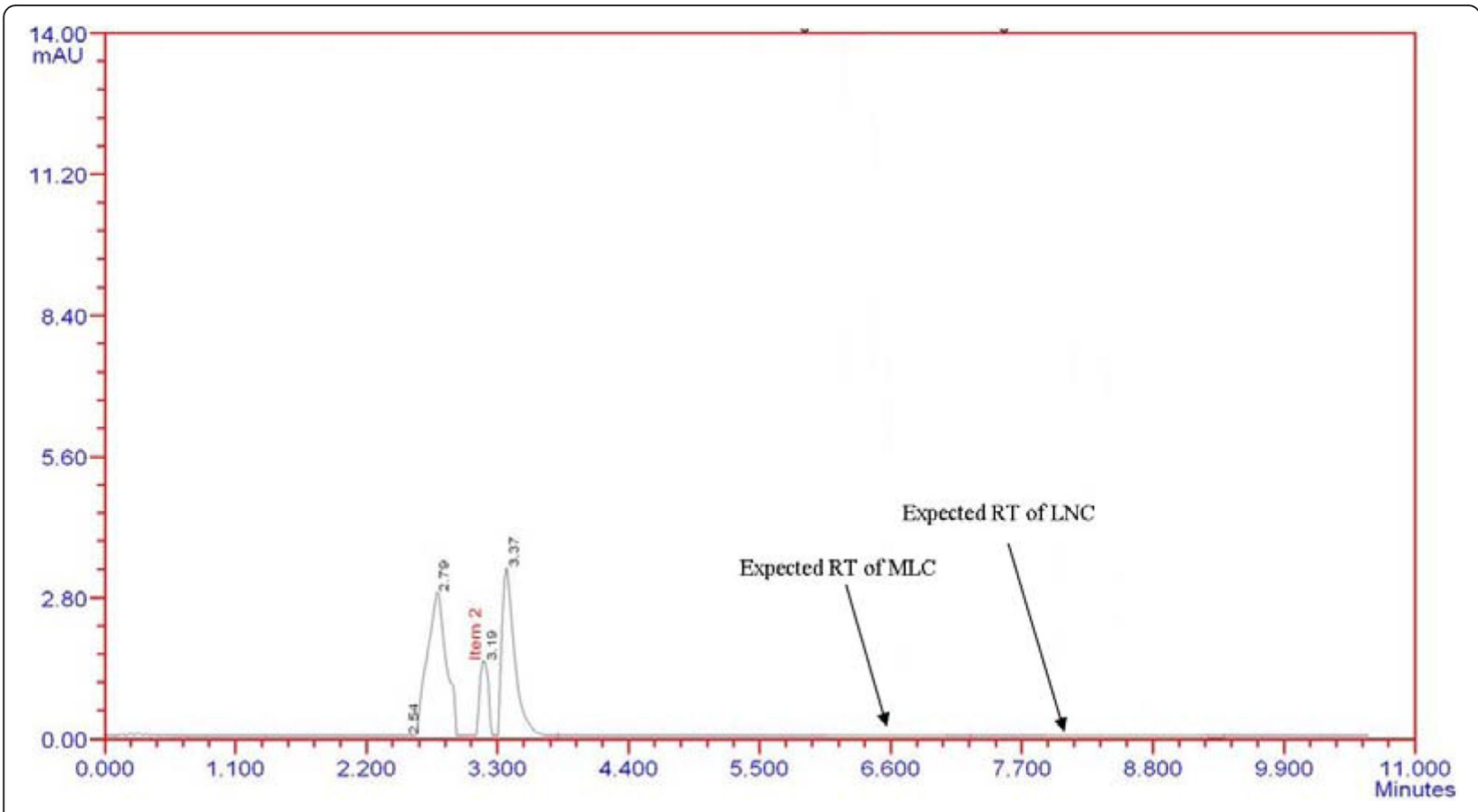

Fig. 2 Typical chromatogram of rabbit blank plasma

MLC in rabbit plasma. \% RSD for the intraday precision and accuracy was noted to be $1.85 \%$ (in RSD) and 98.56\% respectively for MLC. Whereas, an interdays precision of the method was found to be $1.95 \%$ in RSD and the accuracy of the method was found to be $95.98 \%$ for MLC.

\section{Accuracy (\% recovery)}

The absolute recovery of MLC was found to be $91.35 \pm$ $1.55,93.31 \pm 1.66$, and $94.71 \pm 1.43$ for the concentration of $0.50,5.00$, and $20.00 \mu \mathrm{g} \mathrm{mL}{ }^{-1}$ respectively, while the LRC was noted to be $89.85 \pm 1.18$ (Table 3). Moreover, relative recovery of the MLC was determined by comparing the strength of the drug-spiked plasma with the actual added concentration. Relative percent recoveries for $0.50,5.00$, and $20.00 \mu \mathrm{g} \mathrm{mL}^{-1}$ MLC solution were found to be $101.00 \pm 1.97,100.36 \pm 1.85$, and $100.62 \pm$ 0.88 respectively (Table 3 ).

\section{Precision}

The intraday precision of the proposed method was noted to be $1.97,1.85$, and $0.88 \%$ RSD for MLC concentration of $0.50,5.00$, and $20.00 \mu \mathrm{g} \mathrm{mL}{ }^{-1}$ respectively, whereas interday precision was found to $1.09,1.63$, and
$1.60 \mu \mathrm{g} \mathrm{mL} L^{-1} \% \mathrm{RSD}$ for 0.50, 5.00, and $20.00 \mu \mathrm{g} \mathrm{mL} \mathrm{m}^{-1}$ concentration of MLC, respectively. The above results indicated that the method is precise (Table 4). Intraday accuracy was noted to be $101.00,100.36$, and $100.62 \%$ for MLC concentration at $0.50,5.00$, and $20.00 \mu \mathrm{g} \mathrm{mL}$ respectively, while interday accuracy were observed to be 99.36, 98.18, and 98.95 for MLC at concentration 0.50, 5.00 , and $20.00 \mu \mathrm{g} \mathrm{mL}^{-1}$ respectively. The accuracy results also indicate that the proposed method is accurate.

\section{Robustness}

The intentional changes in the method have not been much affected in the selected parameter namely tailing factor, theoretical plates, and the \% assay. Tailing factor, theoretical plate, and percent assay of the MLC were found to be $1.7983 \pm 1.98,2396.93 \pm 1.62$, and $94.59 \pm$ 0.95 after adjustment of $74 \%$ phosphate buffer in the mobile phase respectively, whereas $74 \%$ phosphate buffer was reported to be $1.7033 \pm 1.95,2356.50 \pm 1.55$, and $94.15 \pm 1.08 \%$ respectively. However, changing of flow rate at $0.9 \mathrm{~mL} \mathrm{~min}^{-1}$, tailing factor, theoretical plate, and percent assay were noted to be $1.8233 \pm 1.69,2410.83 \pm$ 1.84 , and $93.57 \pm 0.89 \%$ respectively, while the flow rate of the pump was adjusted at $1.1 \mathrm{~mL} \mathrm{~min}{ }^{-1}$, the tailing

Table 2 Linear regression analysis of calibration curves $(n=6)$

\begin{tabular}{lllllll}
\hline Drug & Linearity range $\left(\mu \mathrm{g} \mathrm{mL} L^{-1}\right)$ & Intercept & Slope & Coefficient of determination $\left(r^{2}\right)$ & $L O D\left(\mu g ~ L^{-1}\right)$ & $L O Q\left(\mu g ~ L^{-1}\right)$ \\
\hline Meloxicam & $0.5-25$ & -576.45 & 1324.25 & 0.9940 & 0.0081 & 0.1035 \\
\hline
\end{tabular}


Table 3 Absolute and relative recovery of MLC and IS $(n=6)$

\begin{tabular}{llll}
\hline Concentration added & & $\begin{array}{l}\text { Absolute recovery } \\
(\text { mean* } \pm \text { RSD) }\end{array}$ & Relative recovery (mean* $\pm \%$ RSD) \\
\hline Meloxicam & $0.50\left(\mu \mathrm{g} \mathrm{mL}^{-1}\right)$ & $91.35 \pm 1.55$ & $101.00 \pm 1.97$ \\
& $5.00\left(\mu \mathrm{g} \mathrm{mL}^{-1}\right)$ & $93.31 \pm 1.66$ & $100.36 \pm 1.85$ \\
& $20.00\left(\mu \mathrm{g} \mathrm{mL}^{-1}\right)$ & $94.71 \pm 1.43$ & $100.62 \pm 0.88$ \\
IS & $5.00\left(\mu \mathrm{g} \mathrm{mL}^{-1}\right)$ & $89.85 \pm 1.18$ & - \\
\hline
\end{tabular}

factor, theoretical plate, and percent assay noted to be $1.8383 \pm 2.00,2426.83 \pm 1.98$, and $92.37 \pm 0.84 \%$ respectively. Moreover, when $\mathrm{pH}$ of the phosphate buffer was changed from 4.7 to 4.6 , the tailing factor, theoretical plate, and \% assay of the MLC was observed to be 1.7350 $\pm 1.54,2274.66 \pm 1.91$, and $92.45 \pm 1.49$, respectively, whereas when $\mathrm{pH}$ was increased from 4.7 to 4.8 , the tailing factor, theoretical plate, and \% assay of the MLC noted to be $1.8433 \pm 1.08,2418.50 \pm 1.82$, and $90.78 \pm 0.80 \%$ respectively. All the results are presented in mean $\pm \%$ RSD.

\section{Stability}

First stability study indicated that even at an ambient temperature $\left(25 \pm 2{ }^{\circ} \mathrm{C}\right)$, MLC spiked rabbit plasma samples remained stable for $24 \mathrm{~h}$ and although at frozen conditions, MLC sample also remained stable for 8 days. Moreover, bench top stability study for MLC sample found to be 98.47 and $99.60 \%$ nominal for low- and high-quality control samples respectively, while 98.74 and $98.27 \%$ nominal for low- and high-quality control samples were reported in the freeze thaw stability study, respectively. In addition, an autosampler stability result of the proposed method found to be 96.57 and $98.44 \%$ nominal for MLC. All the results showed that the approach established is stable for the short term (Table 5).

\section{Pharmacokinetic study}

The developed protein precipitation extraction method was used to determine the bioavailability parameter after oral administration of the MLC bulk drug (reference) and MELFLAM tab (test) sample. Rabbit plasma (blank rabbit plasma), MELFLAM tab (after $1 \mathrm{~h}$ ), and bulk drug suspension (after $1 \mathrm{~h}$ ) were shown in Fig. 3a-c respectively.
Concentration time profiles of MLC in rabbit plasma following oral administration of the test and reference sample at interval $0,0.5,1,2,3,4,6,8,12,24,36$, and $48 \mathrm{~h}$ were presented in Fig. 4 . However, all pharmacokinetic parameters namely $C_{\max }, \mathrm{AUC}_{0-\mathrm{t}}$, $\mathrm{AUC}_{0 \rightarrow \infty}, \mathrm{MRT}, T_{1 / 2}$, and Ke for MLC (test and formulation) were determined after administration of MELFLAM tab formulation and MLC bulk drug using a non-compartmental timing analysis model. $C_{\max }$, $\mathrm{AUC}_{0-\mathrm{t}}$, and $\mathrm{AUC}_{0-\infty}$ were found to be $0.6577 \pm 0.01$, $17.3070 \pm 0.29$, and $25.2047 \pm 0.67 \mu \mathrm{g} \mathrm{mL}{ }^{-1}$ respectively for reference sample, whereas for standard sample, $C_{\max }, \mathrm{AUC}_{0-\mathrm{t}}$, and $\mathrm{AUC}_{0-\infty}$ were noted to be $0.7792 \pm 0.01,19.7973 \pm 1.06$, and $25.1649 \pm 0.89 \mu \mathrm{g}$ $\mathrm{mL}^{-1}$ respectively. In addition, $T_{\max }, T_{1 / 2}$, and MRT of the reference sample were observed to be $6.1 \pm$ $0.36,21.5261 \pm 0.57$, and $31.2453 \pm 0.69 \mathrm{~h}$ respectively, while $4.0 \pm 0.46,20.3629 \pm 0.20$, and $29.3837 \pm$ $0.55 \mathrm{~h} T_{\max }, T_{1 / 2}$, and MRT were found for the test sample. However, Ke for reference and test sample was observed to be $0.0320 \pm 0.01$ and $0.0340 \pm 0.01$, respectively (Table 6), and the two-tailed unpaired student $t$ test was also used to measure the statistical significance for MLC between groups. Geometric mean ratio of $\mathrm{T} / \mathrm{R}$ for $90 \% \mathrm{CI}$ of $C_{\max }, \mathrm{AUC}_{0-\mathrm{t}}$, and $\mathrm{AUC}_{0-\infty}$ were noted to be 118.50 (115.21 and 121.78), 114.57 (106.66 and 122.47), and 100.09 (91.76 and 108.41) \% respectively, which indicate test formulation/reference formulation lies between 80.00 and $125.00 \%$. The $p$ values obtained were noted to be $0.0002,0.9853,0.7709,0.0146,0.9493,0.2436$, and 0.4826 for the $C_{\max }, T_{\max }, T_{1 / 2}, \mathrm{AUC}_{0-\mathrm{t}}, \mathrm{AUC}_{0-\infty}$, MRT, and Ke respectively, which suggested that the

Table 4 Result from study of intraday and interday precision and accuracy for MLC

\begin{tabular}{|c|c|c|c|c|c|c|}
\hline \multirow{3}{*}{$\begin{array}{l}\text { Theoretical } \\
\text { concentration } \\
\left(\mu \mathrm{gL}^{-1}\right)\end{array}$} & \multicolumn{6}{|l|}{ Meloxicam } \\
\hline & \multicolumn{3}{|c|}{ Intraday measured concentration } & \multicolumn{3}{|c|}{ Interdays measured concentration } \\
\hline & $\left(\right.$ mean $^{a} \pm$ S.D $)$ & RSD \% & Accuracy $\%$ & $\left(\right.$ mean $^{b} \pm$ S.D $)$ & RSD \% & Accuracy $\%$ \\
\hline 0.50 & $0.5050 \pm 0.01$ & 1.97 & 101.00 & $0.4968 \pm 0.01$ & 1.09 & 99.36 \\
\hline 5.00 & $5.0183 \pm 0.09$ & 1.85 & 100.36 & $4.9094 \pm 0.08$ & 1.63 & 98.18 \\
\hline 25.00 & $25.1564 \pm 0.22$ & 0.88 & 100.62 & $24.6935 \pm 0.39$ & 1.60 & 98.95 \\
\hline
\end{tabular}

a Values stands for 6 different plasma samples for each concentration

${ }^{b}$ Values stands for 9 different runs over 2-week period 
Table 5 Result from stability study for $\operatorname{MLC}(n=6)$

\begin{tabular}{|c|c|c|c|c|c|c|}
\hline \multirow[t]{2}{*}{ Sr. No. } & \multicolumn{2}{|c|}{ Bench top } & \multicolumn{2}{|c|}{ Freeze thaw } & \multicolumn{2}{|c|}{ Autosampler } \\
\hline & LQC & $\mathrm{HQC}$ & LQC & $\mathrm{HQC}$ & LQC & $\mathrm{HQC}$ \\
\hline 1 & 0.5021 & 25.1013 & 0.5014 & 24.9524 & 0.4895 & 25.0021 \\
\hline 2 & 0.4982 & 24.4566 & 0.4982 & 24.5694 & 0.4789 & 24.1564 \\
\hline 3 & 0.4856 & 25.0012 & 0.4892 & 24.5469 & 0.4625 & 24.9564 \\
\hline 4 & 0.4761 & 24.9816 & 0.4985 & 24.9426 & 0.4892 & 24.5468 \\
\hline 5 & 0.4921 & 24.8564 & 0.4856 & 24.1546 & 0.4911 & 24.4576 \\
\hline 6 & 0.5001 & 25.0021 & 0.4892 & 24.2345 & 0.4856 & 24.5462 \\
\hline Mean & 0.4923 & 24.8998 & 0.4936 & 24.5667 & 0.4828 & 24.6109 \\
\hline S.D. & 0.009 & 0.230 & 0.006 & 0.340 & 0.009 & 0.320 \\
\hline RSD (\%) & 1.82 & 0.93 & 1.31 & 1.38 & 2.07 & 1.30 \\
\hline Nominal (\%) & 98.47 & 99.60 & 98.74 & 98.27 & 96.57 & 98.44 \\
\hline
\end{tabular}

test formulation was quite similar to the reference formulation for pharmacokinetic parameters in MLC. Accordingly, the test and reference formulations were considered to be bioequivalent. All the findings are consistent with previous MLC interaction reports $[1,4,5,7,10,12,14$, 18]. In the final analysis, the results obtained for applying the proposed bioanalytical RP-HPLC approach have shown its efficacy in applying therapeutic drug monitoring and bioequivalence studies.

\section{Discussion}

\section{Optimization of extraction method}

The simple extraction method is important for bioanalysis if you want to progress in extraction efficiency. So, we studied various factors and got them together and the names are as follows, i.e., ion strength, dispersing solvents, $\mathrm{pH}$, sample volume, and applied time. Solvents are very critical in the extraction process, so when selecting the solvent, it must be taken into account high densities, water immiscibility, and high solubility for analytes [38]; thus, the solvent is chosen according to the above. As a result, acetonitrile, diethyl ether, and methanol solvents have therefore been employed for detection of MLC and internal standard from rabbit plasma. In the $\mathrm{ACN}$, the recovery of the MLC and internal standard was better than that of the solvents; in addition, the volume of $\mathrm{ACN}$ in the range of 0.05 to $0.5 \mathrm{~mL}$ should also be checked for better recovery. The best recoveries of the MLC and internal standard have been recorded with $0.1 \mathrm{~mL}$ of acetonitrile extraction solvent; henceforth, $0.1 \mathrm{~mL} \mathrm{ACN}$ volume was continued for the experiment. As a result, an average recovery has been shown to be $98.83 \pm 1.32$ and $93.62 \pm$ $1.47 \%$, respectively, for MLC and LRC.

\section{Optimization chromatographic conditions}

To achieve the greatest selectivity in separating and evaluating target products, optimization of chromatographic
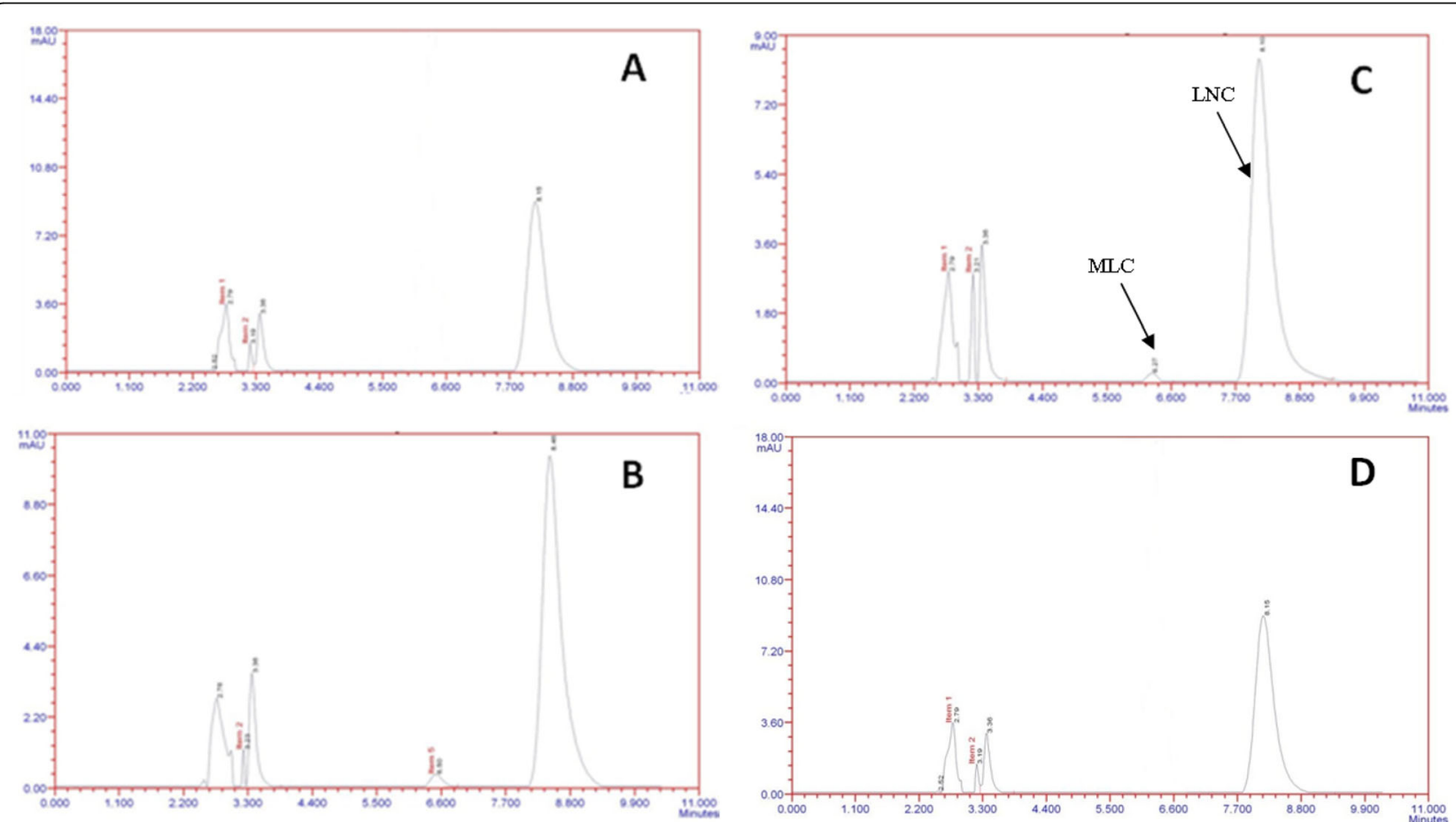

Fig. 3 HPLC chromatograms of rabbit plasma spiked with MLC and collected before (blank plasma) (a), and after 1 h from administration of MELF LAM tab (15 mg) (b) and bulk drug (c) and human blank plasma and IS (d) analyzed by the developed method 


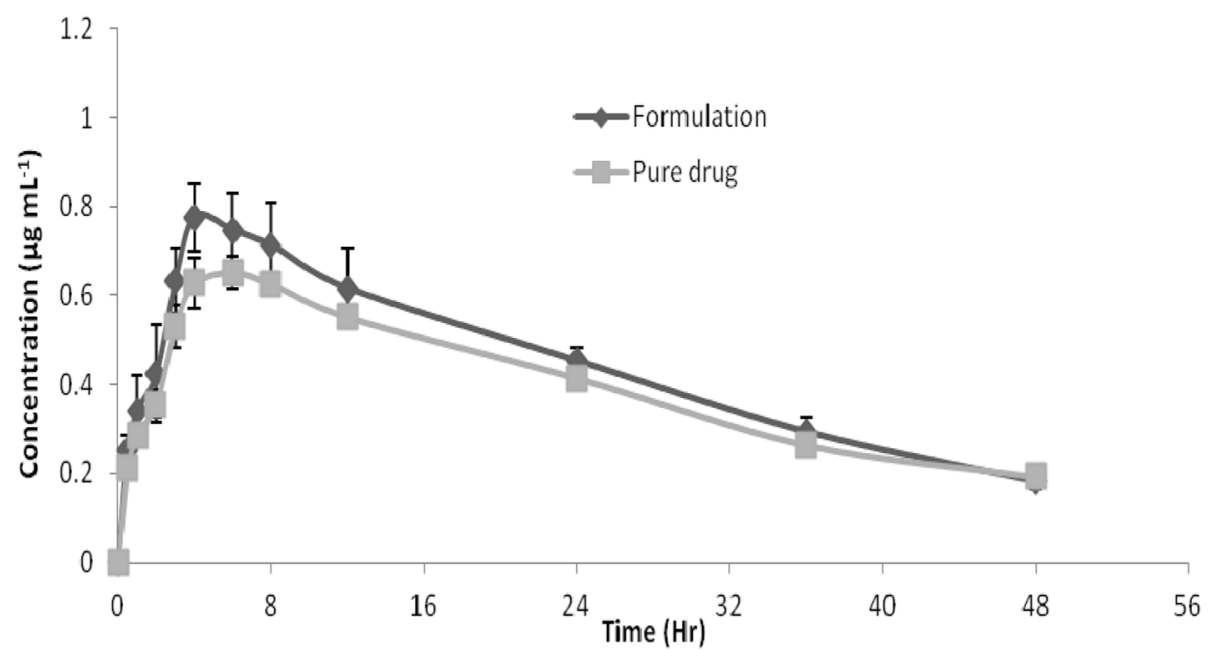

Fig. 4 Plasma concentration-time profiles of MLC in rabbit plasma after oral administration of test and reference sample

conditions is necessary [20]. A variety of chromatographic conditions namely flow rate, $\mathrm{pH}$ of the buffer, ratio of the mobile phase, and different solvents of the mobile phase have been tried to improve the resolution and shape of the peak for MLC and LRC. Nonetheless, various combinations of water, phosphate buffer, methanol, $\mathrm{ACN}$, etc. were tried to set the mobile phase, among them the combination of methanol and phosphate buffer had a good peak shape and also an increased sensitivity over other, but as their volume ratio changed their runtime and resolution was changing. The ratio of methanol and phosphate buffer was therefore maintained at 60:40, so that the runtime and resolution of MLC and LRC would be better. Moreover, the extraction solvent and the LC mobile phase have difference in nature and strength. ACN is a very strong eluting solvent when injected into a LC system with the methanol and buffer as a mobile phase which have potentially impacted on the chromatogram and tailing factor of MLC.
In addition, variability of the phosphate buffer $\mathrm{pH}$ led to poor peak shape (especially at bottom). Finding the right $\mathrm{pH}$ for the phosphate buffer was difficult because $\mathrm{pH}$ of the buffer increased, broadening at MLC and LRC peak base were to be observed. The $\mathrm{pH}$ of the phosphate buffer has therefore been changed to precisely 4.7 by using $o$-phosphoric acid.

Moreover, flow rate parameter was assessed at inter-

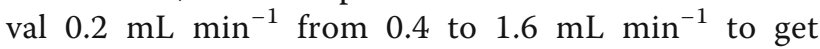
proper resolution and shape of MLC and LRC peak; consequently, MLC and LRC peak merging was observed at a higher range and also high expansion with high resolution of MLC and LRC peak were noted at a

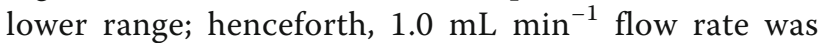
part of optimized chromatographic parameter having better shape of peak. Eventually, the optimized mobile phase consisted of $15 \mathrm{mM}$ phosphate buffer having $\mathrm{pH}$ 4.7: methanol $(40: 60 \mathrm{v} / \mathrm{v})$, with $357.0 \mathrm{~nm} \lambda_{\max }$ of UV

Table 6 Pharmacokinetic parameters of MLC in rabbit plasma after oral administration of MELFLAM tab (15 mg) tablets and Bulk $\operatorname{drug}(n=6)$

\begin{tabular}{|c|c|c|c|c|}
\hline Pharmacokinetic parameter & Reference (mean $\pm \mathrm{SD})$ & Test $($ mean \pm SD) & Geometric mean ratio of T/R $(90 \% \mathrm{Cl})^{\mathrm{a}}$ & $P$ value \\
\hline $\mathrm{Cmax}^{\mathrm{a}}, \mu \mathrm{g} \mathrm{mL^{-1 }}$ & $0.6577 \pm 0.01$ & $0.7792 \pm 0.01$ & $118.50 \%(115.21,121.78)^{b}$ & 0.0002 \\
\hline Tmax, h & $6.1 \pm 0.36(5.8-6.5)$ & $4.0 \pm 0.46(3.5-4.4)$ & - & 0.9853 \\
\hline$T_{1 / 2}, \mathrm{~h}$ & $21.5261 \pm 0.57$ & $20.3629 \pm 0.20$ & - & 0.7709 \\
\hline $\mathrm{A} \cup C O-\mathrm{t}^{\mathrm{a}}, \mu \mathrm{g} \mathrm{h} \mathrm{mL^{-1 }}$ & $17.3070 \pm 0.29$ & $19.7973 \pm 1.06$ & $114.57(106.66,122.47)^{b}$ & 0.0146 \\
\hline $\mathrm{AUCO}-\infty^{\mathrm{a}}, \mu \mathrm{gh} \mathrm{mL^{-1 }}$ & $25.2047 \pm 0.67$ & $25.1649 \pm 0.89$ & $100.09(91.76,108.41)^{b}$ & 0.9493 \\
\hline MRT, h & $31.2453 \pm 0.69$ & $29.3837 \pm 0.55$ & - & 0.2436 \\
\hline Ke & $0.0320 \pm 0.01$ & $0.0340 \pm 0.01$ & - & 0.4826 \\
\hline
\end{tabular}

${ }^{a}$ Bioequivalence criteria are defined as $90 \% \mathrm{Cl}$ of the geometric mean ratios of the test formulation/reference formulation lies between $80.00 \%$ and $125.00 \%$ for

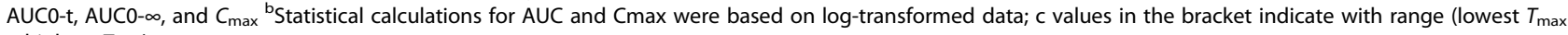
- highest $\left.T_{\max }\right)$ 
detector. During all analytical processes, the retention period for MLC was continuously observed at about $6.2498 \pm 1.4001 \mathrm{~min}$ (Fig. 5). The linear regression of the MLC showed a very significant non-zero intercept. The representative chromatogram rabbit plasma with
LRC is depicted in Fig. 3d. Whereas, Fig. 5a-h illustrates the chromatogram of rabbit blood plasma spiked with MLC and internal standard in the strength of $0.50,1.00,2.00,5.00,10.00,15.00,20.00$, and 25.00 $\mu \mathrm{g} \mathrm{mL} \mathrm{L}^{-1}$ respectively.
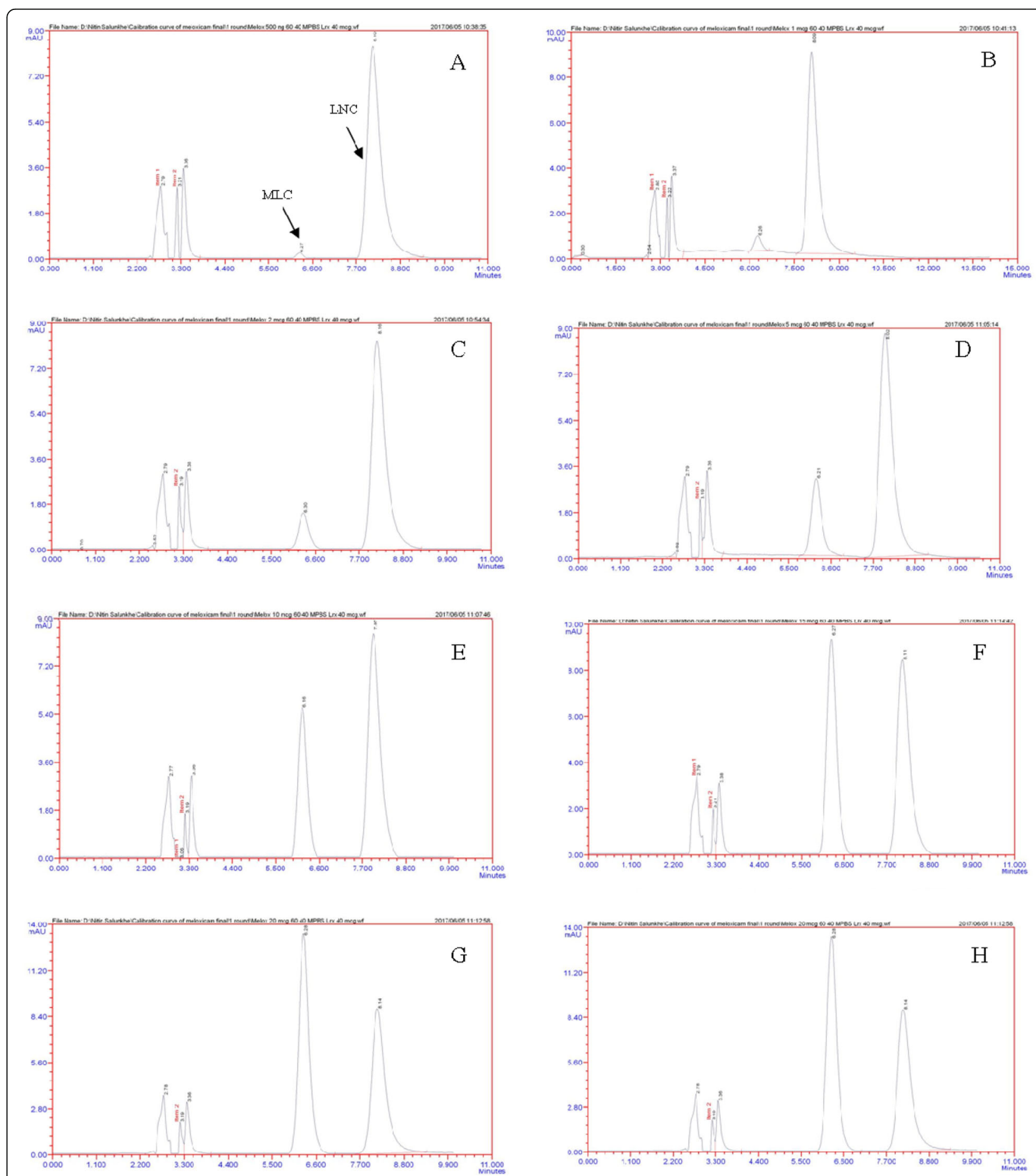

Fig. 5 Typical chromatogram obtained for rabbit plasma spiked with a 0.50 , b 1.00, c 2.00, d 5.00, e 10.00, f 15.00, g 20.00, and h $25.00 \mu \mathrm{g} \mathrm{mL} \mathrm{L}^{-1}$ MLC and LNC as IS 


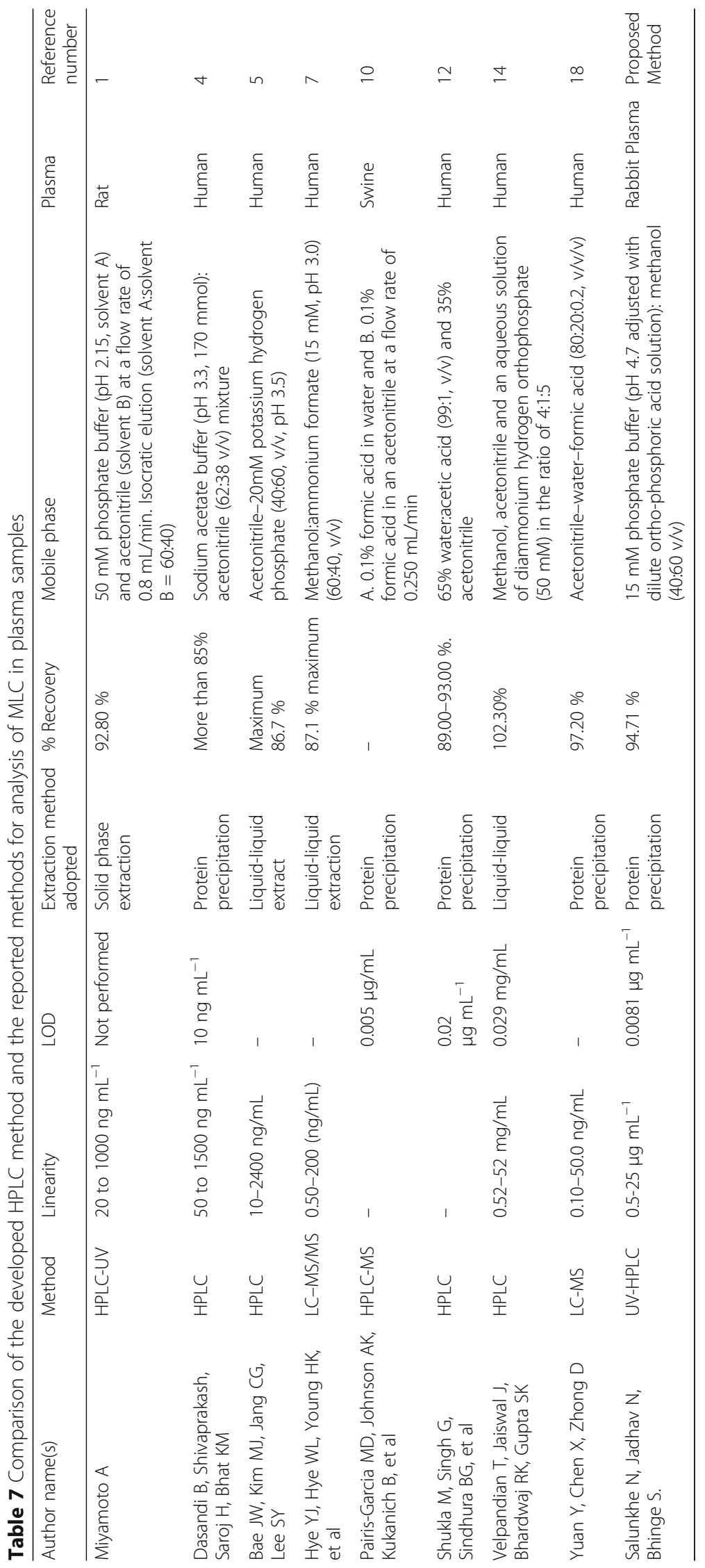




\section{Pharmacokinetic study}

The proposed approach was effectively implemented in the pharmacokinetic and bioequivalence studies following a single oral dose of MLC bulk drugs and the formulation of MELFLAM tab (15 mg) tablets in rabbit. MELFLAM tab (15 $\mathrm{mg})$ is the product of zydus cadila also prescribed regularly in the region of Karad taluka, Maharashtra-415110. We have served in our region, and most of the doctors prefer the MELFLAM tab to their patients, and therefore we have chosen the said brand for the pharmacokinetic study of the developed method.

Different parameters were verified for the bioequivalance study of bulk drug as reference and MELFLAM tab formulation as test sample of MLC. However, oral suspension of the formulation of MELFLAM tab and bulk drugs were well tolerated by the respective rabbit group and no adverse reactions were observed. Subsequently, rabbit blood plasma of respective groups was tested in HPLC until $48 \mathrm{~h}$ for the pharmacokinetic approach. Experimental pharmacokinetic parameters, test/reference ratio (T/R), confidence intervals (90 CIs), and their significant statistical numbers for MLC following oral administration of $15 \mathrm{mg}$ of MELFLAM tablets ranged from 80 to $125 \%$ in accordance with the FDA Bioequivalence Guideline for $\mathrm{AUC}_{\mathrm{o}-\mathrm{t}}, \mathrm{AUC}_{0_{-\infty}}$, and $C_{\max }[39,40]$.

\section{Figure of merits}

Miyamoto et al. [1] have developed a solid-phase extraction approach for the estimation of MLC from biological sample, which have required extra assembly for the extraction process, while Bae et al. [5], Hye et al. [7], and Velpandian et al. [14] have developed a biological method for the estimation of MLC using a liquid-liquid extraction procedure due to the high plasma protein binding characters of MLC that make its complete extraction from plasma suspicious. Moreover Dasandi et al. [4], Pairis-Garcia et al. [10], Shukla et al. [12], and Yuan et al. [18] have used protein precipitation method which is a cost-effective method than abovementioned (Table 7). However, Pairis-Garcia et al. [10] and Shukla et al. [12] have not clearly mentioned the linearity range of meloxicam, while Yuan et al. [18] have used limited validation parameter (excluding LOD, LOQ, etc.). Moreover, Dasandi et al.'s method have followed all validation parameter but recovery of MLC is less than the proposed method (Table 7). Nonetheless, the results of recovery for MLC using $0.1 \mathrm{~mL}$ ACN proved that the protein precipitation approach is suitable for MLC quantification and also has high extraction efficiency. Method reproducibility at short times is of major concern in rabbit plasma determination. The process is non-tedious and substantially time consuming compared to the other method, which takes approximately $13 \mathrm{~min}$ to extract the MLC and internal standard with high reproducibility absolutely. Therefore, the expense of testing diminished only was $100 \mu \mathrm{L}$ of rabbit plasma and $\mathrm{ACN}$ solvent. While the extraction processes have been performed in a simple step, manipulation in a short time is still easy. The validation and bioequivalence results proved the usefulness of the developed biological method in analysis of MLC with LRC.

\section{Conclusion}

In conclusion, an optimized and established bioanalytical method for quantification of Meloxicam is selective, precise, accurate, fast, and sensitive. Furthermore, Meloxicam analyte was extracted from biological sample of rabbit with simple extraction process and proved the bioequivalence of bulk drug sample and selected tablet formulation which could aid in therapeutic drug monitoring and bioavailability studies.

\section{Abbreviations \\ ANOVA: Analysis of variance; AUC: Area under curve; $C_{\text {max }}$ : Maximum peak plasma concentration; MRT: Mean residence time; LRC: Lornoxicam; MLC: Meloxicam; LOD: Limit of detection; LOQ: Limit of quantification; LQC: Lower quality control sample; MQC: Medium quality control; HQC: Higher quality control; ACN: Acetonitrile; RSD: Relative standard deviation}

\section{Acknowledgements}

Authors are thankful to Dr. H. N. More, Principal, BV College of Pharmacy, Kolhapur (MS), INDIA for providing necessary facilities to carry out the research work.

\section{Authors' contributions}

NRJ, NS, and SDB carried out the study designs. NRJ, NS, and SDB execution of the proposed study and drafting of manuscript. NRJ, NS, and SDB participated in in vivo studies and performed this statistical analysis. All authors have read and approved the manuscript.

\section{Funding}

No funding.

Availability of data and materials

Data and material are available upon request.

\section{Ethics approval and consent to participate}

The research work was approved by Bharati Vidyapeeth College of Pharmacy, Kolhapur, Maharashtra, INDIA as per guidelines of CPCSEA; (Approval no. BVCPK/CPCSEA/IAEC/01/05).

\section{Consent for publication}

Not applicable.

\section{Competing interests}

The authors declare that they have no competing interest.

\section{Author details}

'Department of Pharmaceutics, Bharati Vidyapeeth College of Pharmacy, Kolhapur, Maharashtra 416013, India. ${ }^{2}$ Adarsh College of Pharmacy, Vita, Maharashtra 415311, India. ${ }^{3}$ Rajarambapu College of Pharmacy, Kasegaon, Sangli, Maharashtra 415404, India. 
Received: 4 January 2020 Accepted: 6 August 2020

\section{Published online: 30 September 2020}

\section{References}

1. Miyamoto A, Aoyama T, Matsumoto Y (2017) The measurement of meloxicam and meloxicam metabolites in rat plasma using a highperformance liquid chromatography-ultraviolet spectrophotometry method. Chem. Pharm. Bull. 65(2):121-126. https://doi.org/10.1248/cpb.c16-00514

2. Fleischmann R, lqbal I, Slobodin G (2002) Drug evaluation Meloxicam. Expert opinion pharmacother. 3(10):1501-1512. https://doi.org/10.1517/14656566.3. 10.1501

3. Reynolds EF (1999) Martindale The Extra Pharmacopoeia, 32nd edn. The Royal Pharmaceutical Society, London

4. Dasandi B, Shivaprakash SH, Bhat KM (2002) LC determination and pharmacokinetics of meloxicam. J Pharm Biomed Anal. 28(5):999-1004. https://doi.org/10.1016/S0731-7085(02)00064-X

5. Bae JW, Kim MJ, Jang CG, Lee SY (2007) Determination of meloxicam in human plasma using a HPLC method with UV detection and its application to a pharmacokinetic study. J Chromatogr B: Anal Tech Biomed Life Sci. 859(1):69-73. https://doi.org/10.1016/j.jchromb.2007.09.004

6. Hassan EM (2002) Spectrophotometric and fluorimetric methods for the determination of meloxicam in dosage forms. J Pharm Biomed Anal. 27(5): 771-777. https://doi.org/10.1016/S0731-7085(01)00530-1

7. Hye YJ, Hye WL, Young HK, Dong WJ, Lee HS (2005) Simultaneous determination of piroxicam, meloxicam and tenoxicam in human plasma by liquid chromatography with tandem mass spectrometry. J Chromatogr B: Anal Tech Biomed Life Sci. 826(1-2):214-219. https://doi.org/10.1016/j. jchromb.2005.08.023

8. Louati K, Bargaoui I, Safta F (2018) Development and validation of ultraperformance liquid chromatography method for the determination of meloxicam and its impurities in active pharmaceutical ingredients. Ann Pharm Fr. 76(3):187-200. https://doi.org/10.1016/j.pharma.2018.02.001

9. Nemutlu E, Kir S (2003) Method development and validation for the analysis of meloxicam in tablets by CZE. J Pharm Biomed Anal. 31(2):393-400. https://doi.org/10.1016/S0731-7085(02)00641-6

10. Pairis-Garcia MD, Johnson AK, Kukanich B, Wulf L, Millman ST, Stalder KJ, Karriker LA, Coetzee JF (2015) Pharmacokinetics of meloxicam in mature swine after intravenous and oral administration. J Vet Pharmacol Ther. 38(3): 265-270. https://doi.org/10.1111/jvp.12170

11. Sahoo NK, Sahu M, Rao PS, Sandhya Rani N, Indira Devi JNV, Ghosh G (2014) Validation of assay indicating method development of Meloxicam in bulk and some of its tablet dosage forms by RP-HPLC. SpringerPlus. 3(1):1-6. https://doi.org/10.1186/2193-1801-3-95

12. Shukla M, Singh G, Sindhura BG, Telang AG, Rao GS, Malik JK (2007) Comparative plasma pharmacokinetics of meloxicam in sheep and goats following intravenous administration. Comp Biochem Physiol C Toxicol Pharmacol. 145(4):528-532. https://doi.org/10.1016/j.cbpc.2007.01.020

13. Van Pamel E, Daeseleire E (2015) A multiresidue liquid chromatographic/ tandem mass spectrometric method for the detection and quantitation of 15 nonsteroidal anti-inflammatory drugs (NSAIDs) in bovine meat and milk. Anal bioanal chem. 407(15):4485-4494. https://doi.org/10.1007/s00216-015-8634-1

14. Velpandian T, Jaiswal J, Bhardwaj RK, Gupta SK (2000) Development and validation of a new high-performance liquid chromatographic estimation method of meloxicam in biological samples. J Chromatogr B. 738:431-436

15. Vignaduzzo SE, Castellano PM, Kaufman TS (2008) Method development and validation for the simultaneous determination of meloxicam and pridinol mesylate using RP-HPLC and its application in drug formulations. J Pharm Biomed Anal. 46(2):219-225. https://doi.org/10.1016/j.jpba.2007.09.011

16. Wiesner J, Sutherland FC, van Essen G, Hundt HK, Swart K, Hundt A (2003) Selective, sensitive and rapid liquid chromatography-tandem mass spectrometry method for the determination of alfuzosin in human plasma. J Chromatogr B. 788:361-368. https://doi.org/10.1016/S1570-0232(03)00064-3

17. Wu X, Cao H, Zhao L, Song J, She Y, Feng Y (2016) Metabolomic analysis of glycerophospholipid signatures of inflammation treated with non-steroidal anti-inflammatory drugs-induced-RAW264.7 cells using1H NMR and UHPLC/Q-TOF-MS. J Chromatogra B: Anal Tech Biomed Life Sci. 1028:199_ 215. https://doi.org/10.1016/j.jchromb.2016.06.032

18. Yuan Y, Chen X, Zhong D (2007) Determination of meloxicam in human plasma by liquid chromatography-tandem mass spectrometry following transdermal administration. J Chromatogra B: Anal Tech Biomed Life Sci. 852(1-2):650-654. https://doi.org/10.1016/j.jchromb.2007.01.036
19. Kallem RR, Ramesh M, Seshagirirao JVLN (2013) Validated LC-ESI-MS/MS method for simultaneous quantitation of felodipine and metoprolol in rat plasma: application to a pharmacokinetic study in rats. Biomed Chromatogr. 27(6):784-791. https://doi.org/10.1002/bmc.2861

20. Ahmed S, Atia NN, Ali MFB (2017) Ultrasound assisted dispersive liquidliquid microextraction coupled with high performance liquid chromatography designated for bioavailability studies of felodipine combinations in rat plasma. J Chromatogra B: Anal Tech Biomed Life Sci. 1046:200-210. https://doi.org/10.1016/j.jchromb.2017.01.034

21. Xu X (2005) Rapid LC/MS/MS Method development for drug discovery a three-checkpoint paradigm. Anal chem. 77(19):389-394

22. Guidance for industry: bioavailability and bioequivalence studies for orally administered drug products-general considerations. U.S. Department of Health and Human Services Food and Drug Administration Center for Drug Evaluation and Research. (2003).

23. Guidance for Industry-Bioanalytical Method Validation. U.S. Department of Health and Human Services, USFDA. (2001).

24. Sane RT, Menon S, Deshpande AY, Jain A (2005) HPLC determination and pharmacokinetic study of valdecoxib in human plasma. Chromatogr. 61(34):137-141. https://doi.org/10.1365/s10337-004-0442-2

25. Dange Y, Bhinge S, Salunkhe V (2017) Optimization and validation of RP-HPLC method for simultaneous estimation of palbociclib and letrozole. Toxicol Mech Methods. 28(3):187-194. https://doi.org/10.1080/15376516.2017.1388458

26. Q2A ICH guideline, Validation of analytical procedures text methodology. (2003).

27. Bhinge SD, Malipatil SM, Sonawane LV (2014) Bioanalytical method development and validation for simultaneous estimation of cefixime and dicloxacillin by RP-HPLC in human plasma. Acta Chim Slov. 61(3):582-586

28. EMA: Guideline on bioanalytical method validation. Committee for medicinal products for human use. (2011). EMEA/CHMP/EWP/192217/2009

29. Guidance for Industry on Bioanalytical Method Validation. Fed. Regist., Rockville, MD: 18. Department of Health and Human Services, Food and Drug Administration. (2001).

30. Patil KM, Bodhankar SL (2005) Simultaneous determination of lamotrigine, phenobarbitone, carbamazepine and phenytoin in human serum by highperformance liquid chromatography. J Pharm Biomed Anal. 39(1-2):181186. https://doi.org/10.1016/j.jpba.2005.02.045

31. Bhinge SD, Malipatil SM, Jondhale A, Savali AS (2013) Simultaneous estimation of atorvastatin calcium and fenofibrate in rabbit plasma by RPHPLC. Asian J Chem. 25(2):981-985

32. Bhinge SD, Malipatil SM, Sonawane LV (2012) Simultaneous estimation of cefixime and cloxacillin in human plasma by reversed phase-HPLC with UV detection. Thai J Pharm Sci. 36(2):63-71

33. Salunkhe NH, Jadhav NR, Bhinge SD (2018) Validated RP-HPLC method for quantification of felodipine in rabbit plasma: Application in a bioequivalence study. Ann Pharm Fr. 77(1):15-19. https://doi.org/10.1016/j. pharma.2018.08.002

34. Shermer S (1967) The Blood Morphology of Laboratory Animals, 3rd edn. F. A. Davis Company, Philadelphia, USA

35. Bolton S, Charles B. Experimental Design in Clinical trials. In: Pharmaceutical StatisticsPractical and Clinical Applications ( $5^{\text {th }}$ edn), New York: Marcel Dekker Inc. 384-443, 2008.

36. Muralidharan S, Krishnan NJS, Singh S, Anil D (2012) Bioequivalence Study of Simvastatin. Open scientific reports. 1:438. https://doi.org/10.4172/ scientificreports.438

37. The United States Pharmacopoeia 35 National formulary 30. Eas-ton; R and Mc Nally Taunton. (2012).

38. Rezaee M, Yamini Y, Faraji M (2010) Evolution of dispersive liquid-liquid microextraction method. J Chromatogr A. 1217(16):2342-2357. https://doi. org/10.1016/j.chroma.2009.11.088

39. FDA (1993) In vivo bioequivalence guidances. Pharmacopeial forum, US Department of Health and Human Service, Food and Drug Administration, Rockville, MD, USA 19:6501-6508

40. Salunkhe N, Jadhav N, Bhinge S (2019) Lornoxicam quantification in rabbit plasma by reverse phase HPLC: Optimization and application to pharmacokinetic study. Sep sci plus. 2(11):405-415. https://doi.org/10.1002/ sscp.201900061

\section{Publisher's Note}

Springer Nature remains neutral with regard to jurisdictional claims in published maps and institutional affiliations. 